\title{
O BIM INTEGRADO NOS PROCESSOS DE DOCUMENTAÇÃO DO PROJETO DE ARQUITETURA E COLABORAÇÃO INTERDISCIPLINAR. O CASO DA ESTAÇÃO DE SIDI BEL ABBÈS
}

\author{
Daniel Moutinho ${ }^{(1)}$ \\ (1) TPF - CONSULTORES DE ENGENHARIA E ARQUITETURA S.A., Lisboa
}

\begin{abstract}
Resumo
No Departamento de Estudos e Projetos da TPF - CONSULTORES DE ENGENHARIA E ARQUITETURA S.A., a metodologia BIM foi implementada com o objetivo de aumentar a eficiência dos processos envolvidos, tanto os que dizem respeito à colaboração interdisciplinar, como à produção da documentação do projeto de Arquitetura entregue ao cliente. Para o demonstrar, usamos como exemplo o projeto da Estação de Sidi Bel Abbès, na Argélia.

Os processos BIM foram sendo integrados nos fluxos de trabalho do projeto de modo gradual, conciliando o nível de maturidade BIM da equipa com as necessidades de documentação do projeto. Os usos BIM [1] abordados no presente artigo são os seguintes:
\end{abstract}

- Produção automática de peças desenhadas;

- Revisão do projeto pelo Dono de Obra;

- Colaboração e Coordenação 3D;

- Quantificação automática e orçamentação.

\section{Introdução}

A metodologia BIM, ao dispor dos arquitetos e de todos os profissionais da indústria da construção, envolve meios altamente tecnológicos que aceleram o desenvolvimento do projeto, tornando os processos envolvidos mais eficientes.

O projeto que se aborda no presente artigo foi desenvolvido entre 2015 e 2018 . Trata-se de um período relativamente longo que permitiu que o trabalho fosse evoluindo com o nível de maturidade BIM da equipa de projeto. Neste sentido, os usos BIM implementados foram introduzidos de forma gradual: uns de imediato, desde a fase inicial; outros implicaram um planeamento cuidado, com base num BIM Execution Plan (BEP) [2], para as fases mais exigentes em termos de coordenação e colaboração interdisciplinar. Nos capítulos seguintes apresentamos os detalhes de cada uso implementado, segundo a ordem com que foi introduzido 
no projeto, mas antes, em modo de contextualização, apresentamos algumas considerações sobre o Dono de Obra (DO), a Equipa de Projeto e a Proposta Arquitetónica.

\subsection{O Dono de Obra}

A Agence Nationale d'Études et de Suivi de la Réalisation des Investissements Ferroviaires, ANESRIF, é uma empresa criada pelo governo argelino para expandir e modernizar o sistema ferroviário. É representada por um Diretor Geral, assessorado por especialistas em diversas matérias. Ao longo do projeto, que envolveu 3 fases - Esquisse, Avant Projet Sommaire e Avant Projet Détaillé (que correspondem aproximadamente às fases Estudo Prévio, Anteprojeto e Projeto de Execução), houve uma substituição do Diretor Geral, o que se traduziu numa alteração da abordagem ao projeto por parte do Cliente.

Embora o uso da metodologia BIM não tenha sido uma exigência do DO, este acabou por beneficiar desde muito cedo de outputs que lhe proporcionaram uma perceção muito fiel da evolução do projeto, o que lhe permitiu ponderar muito bem as suas decisões.

\subsection{A Equipa de Projeto}

O projeto surge num período em que a empresa estava a reunir condições para implementar a metodologia BIM de modo a tornar-se mais eficiente. Embora se reconhecesse que o seu nível de maturidade BIM não era suficiente para a gestão de informação típica de fases de projeto avançadas, entendeu-se que o risco de insucesso seria muito limitado, uma vez que o projeto estava a começar e envolvia, por isso, poucos meios humanos.

A fase de Esquisse prolongou-se durante quase 2 anos, com diversas interações e períodos de tomada de decisão bastante prolongados. Durante este tempo, o nível de maturidade BIM da equipa foi aumentando de modo estruturado. Quando o projeto avançou para fases mais complexas, conseguiu-se que o projeto em BIM extravasasse a Arquitetura e se prolongasse em modo colaborativo para a maioria das disciplinas envolvidas (Figura 1).

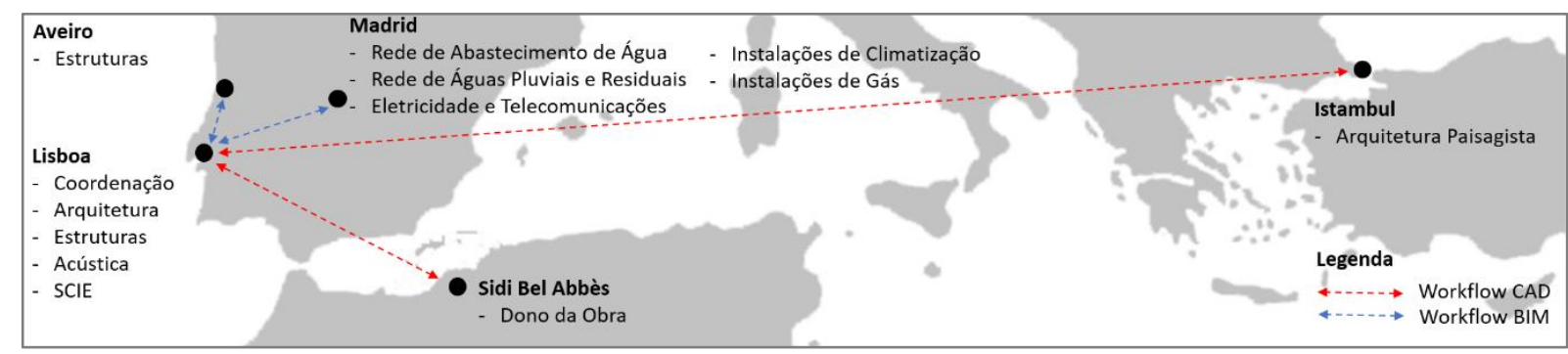

Figura 1: Distribuição geográfica dos vários intervenientes no projeto.

A variedade de fluxos de trabalho, divididos entre os suportados em processos BIM e os suportados em processos $\mathrm{CAD}$, associado ao facto dos vários intervenientes se encontrarem geograficamente dispersos, revelou-se um desafio extremamente enriquecedor para coordenação do projeto e sedimentação de processos na empresa.

\subsection{Proposta Arquitetónica}

O conceito apresentado para a estação (Figura 2) tem como base dois elementos com objetivos muito distintos: 
- A Forma da cobertura, de geometria simples, de planta elíptica, mas de concretização extravagante, por apresentar uma secção com vertentes laterais muito pronunciadas, explora as noções de movimento, Landmark e escala humana versus escala urbana;

- O Muro, que confina as plataformas de embarque, para além de ganhar espessura para acolher dependências funcionais no seu interior, confere uma base de suporte e sustentação para a cobertura e define um limite físico que remata numa parte da cidade que se encontra difusa, fragmentada e em consolidação.

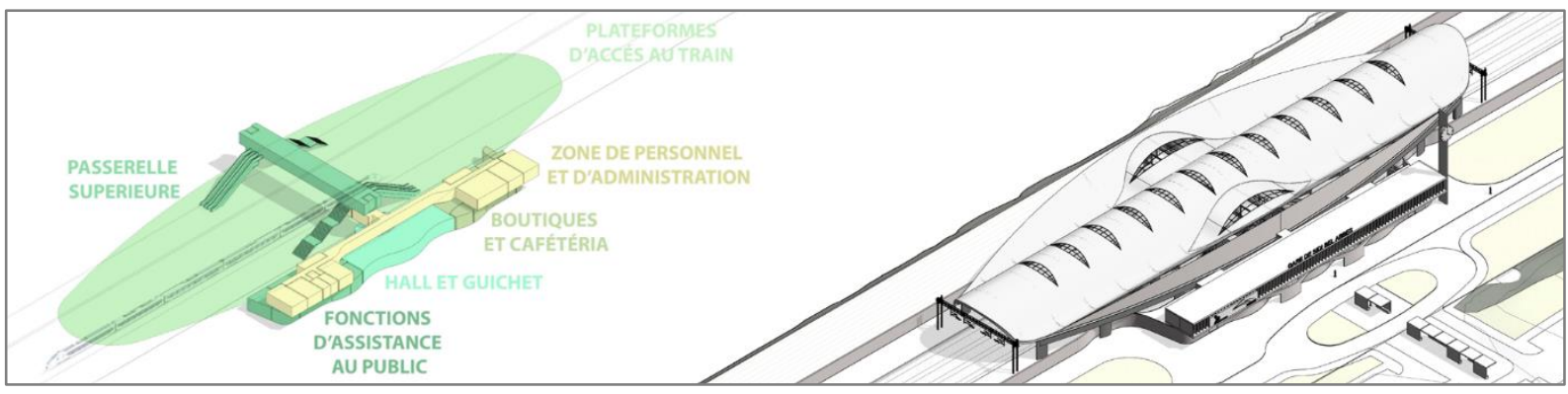

Figura 2: Distribuição Funcional e concretização volumétrica.

Todas estas temáticas foram abordadas com base no suporte documental produzido na plataforma BIM de modelação, no âmbito da fase de Esquisse. Durante esta fase, o projeto foi amadurecendo com alterações drásticas de áreas de construção, novas funções e relações funcionais entres as diferentes dependências, alteração de pisos, entre outras transformações. Em conjunto com o DO, o conceito foi ganhando força e sustentação.

\section{Produção automática de peças desenhadas}

Este tema é estruturado com base em dois momentos muito distintos no projeto: numa primeira fase, as capacidades da plataforma usada surtiram efeitos muito rápidos na melhoria da qualidade e quantidade da informação produzida a partir dos mecanismos de automatização de produção de desenhos; nas fases posteriores, a automatização pretendida, principalmente no que respeita à anotação dos pormenores construtivos, apenas revela o seu potencial na sequência de um grande esforço de modelação e sistematização de informação.

\subsection{Quantidade e qualidade da informação produzida}

A plataforma de modelação utilizada no desenvolvimento do projeto de arquitetura foi o Autodesk Revit. O entusiasmo em torno do software prendia-se com a sua utilidade mais imediata, que era satisfazer, de modo expedito, as necessidades de representação da documentação desenhada do projeto.

Com base nos requisitos do projeto, o primeiro entregável a executar era um organograma a relacionar funcionalmente as várias dependências expressas no programa preliminar. Contudo, a equipa conseguiu com facilidade superar as expectativas do DO, adicionando plantas e visualizações 3D esquemáticas com camadas de informação que permitiram abordar com o cliente temas complexos que extravasavam a orgânica interna do edifício (Figura 3). 


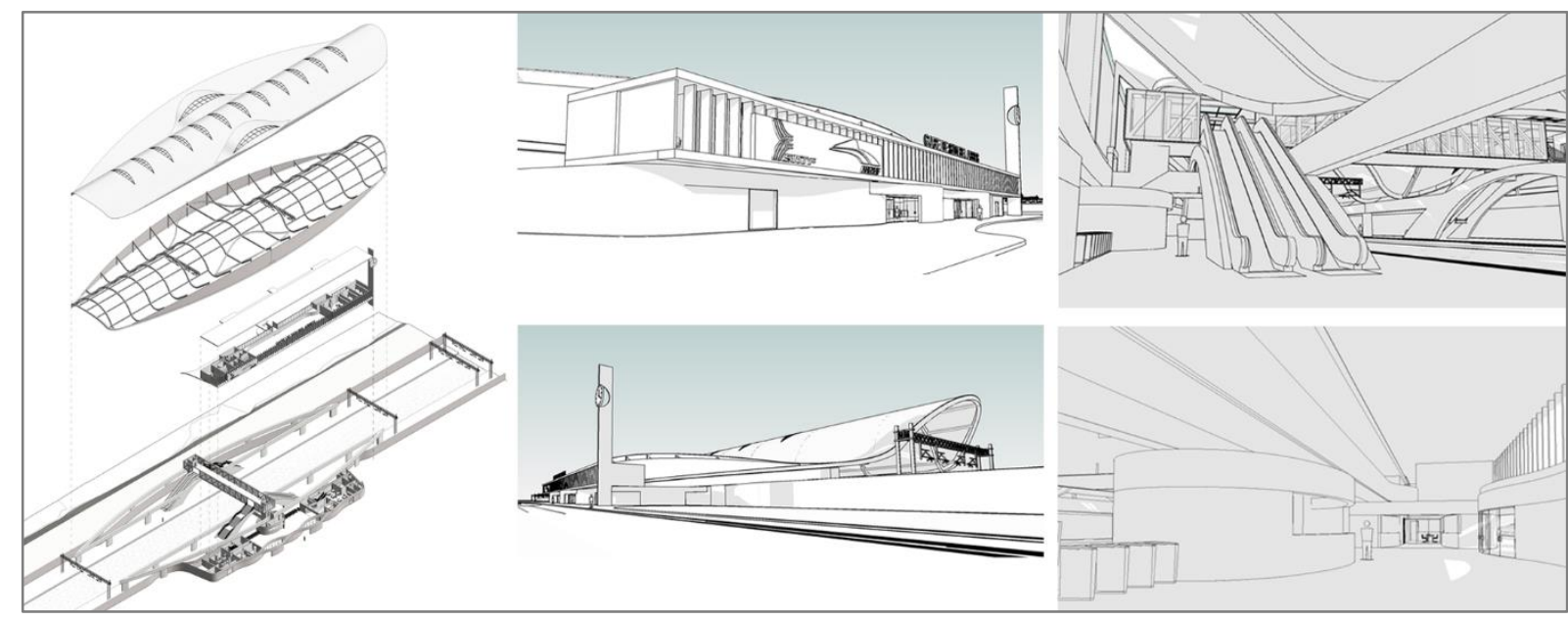

Figura 3: Exemplos de visualizações 3D fornecidas no âmbito da fase de Esquisse.

Esta melhoria aproximou o DO de questões relacionadas com a forma, identidade arquitetónica, a sua materialidade e técnicas de construção, a escala humana e escala urbana do edifício, a sua importância no contexto do sistema de transportes públicos da cidade, e a sua relevância como Landmark numa zona periférica da cidade, em consolidação.

\subsection{Pormenorização construtiva e descrição dos elementos}

Na fase de maior complexidade, Avant Projet Détaillé, introduziu-se um novo processo de modo a tirar partido da informação já sistematizada para projetos com base em processos CAD. Este procedimento implica a interoperabilidade de software distinto: o Autodesk Revit e o Microsoft Excel. A sua relação tem como base a utilização do parâmetro keynote no Revit que está disponível em todos os elementos do modelo e materiais. A identificação destes elementos é feita usando uma família de anotação para identificação de keynotes. A codificação e a descrição de cada keynote resultam de um arquivo de texto (.txt) independente do modelo que contém a lista de keynotes. A gestão de dados é realizada via Excel, plataforma a partir da qual se exporta o arquivo de texto que será lido no Revit (Figura 4).

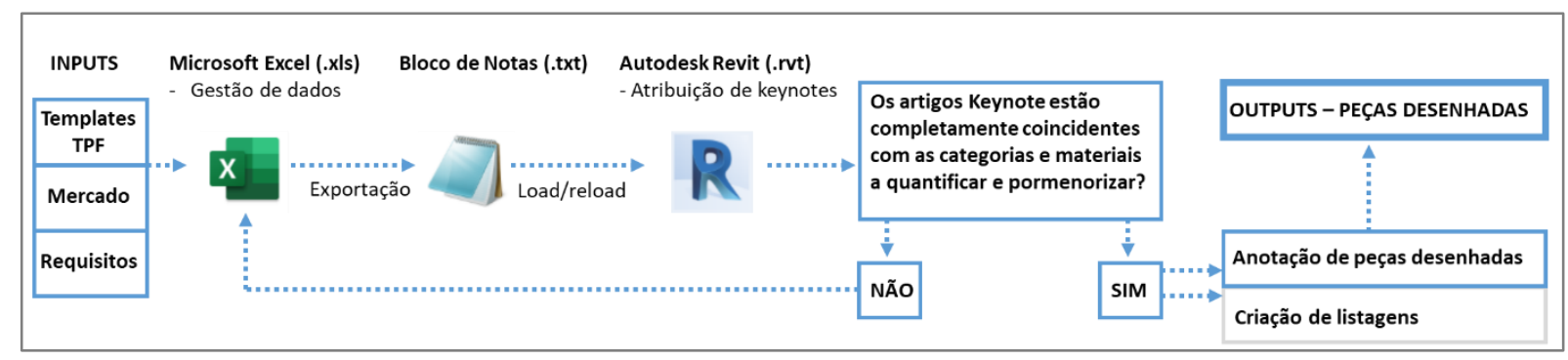

Figura 4: Diagrama do processo de anotação no âmbito da pormenorização construtiva.

Em termos práticos, o processo consiste no seguinte: em paralelo com a evolução do modelo BIM em Revit, desenvolve-se uma lista de todos os materiais e trabalhos existentes no projeto de arquitetura num ficheiro Excel. A lista é estruturada com os artigos e respetivas descrições que farão parte do output do Mapa de Quantidades. Este ficheiro, depois de convertido para .txt, é lido pelo Revit por forma a que seja possível a associação de cada artigo ao parâmetro 
keynote existente em cada elemento do modelo BIM. Deste modo, cada artigo que consta do mapa de quantidades, tanto a sua codificação, como descrição, surge na pormenorização construtiva, evitando incompatibilidades entre estes dois elementos do projeto.

\section{Revisão do projeto pelo Dono de Obra}

O DO acompanha o desenvolvimento do projeto com base nos outputs que vai recebendo, fase a fase (Figura 5). As suas decisões são tanto mais consequentes e informadas, quanto melhor for o seu entendimento do projeto. Nos tópicos seguintes, pretendemos demonstrar em que medida foi possível melhorar o processo de criação de imagens 3D foto-realistas e integrar a Realidade Virtual como um novo entregável de projeto.

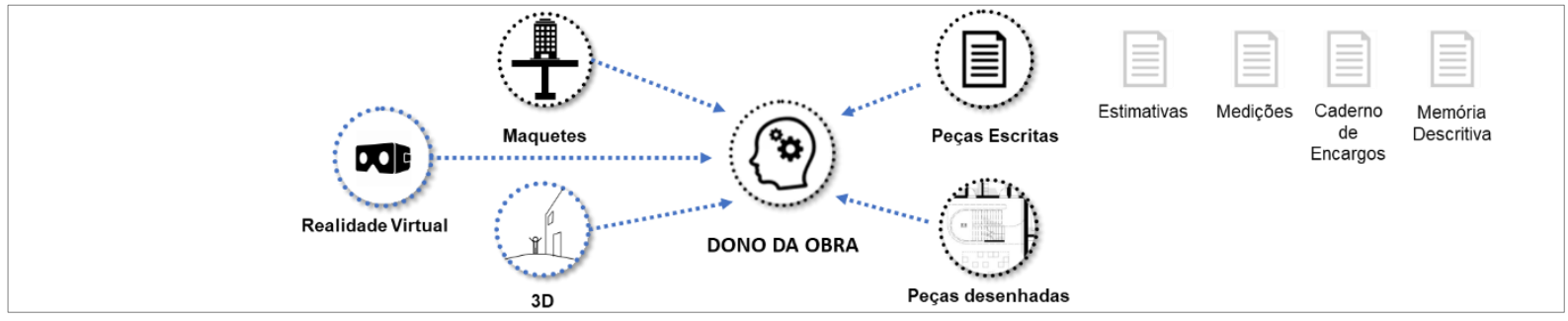

Figura 5: Diagrama dos outputs de projeto fornecidos ao Dono de Obra.

\subsection{Visualizações tridimensionais foto-realistas}

A metodologia BIM permitiu enriquecer as peças desenhadas com Axonometrias e imagens tridimensionais que são um subproduto direto do modelo BIM. Este facto levou também à agilização do processo de criação das imagens tridimensionais foto-realistas em software específico, na medida em que, ao contrário do processo tradicional, o modelo tridimensional não precisa de ser especialmente gerado para este efeito, pois já existe. Embora o Revit seja um software de capacidades muito abrangentes, consideramos que para renderização foto-realista não é o mais adequado.

O processo de geração das imagens foto-realistas é iniciado com a exportação do modelo BIM para o formato. skp (Trimble sketchUp) recorrendo ao plugin rvt2skp. Posteriormente, no SketchUp, procede-se para refinamento das texturas dos materiais e renderização foto-realista com o plugin Vray. A pós-produção é realizada em Adobe Photoshop. Para o melhoramento de cada imagem, o ciclo atrás descrito é repetido até se conseguir o resultado satisfatório para apresentação ao DO (Figura 6).
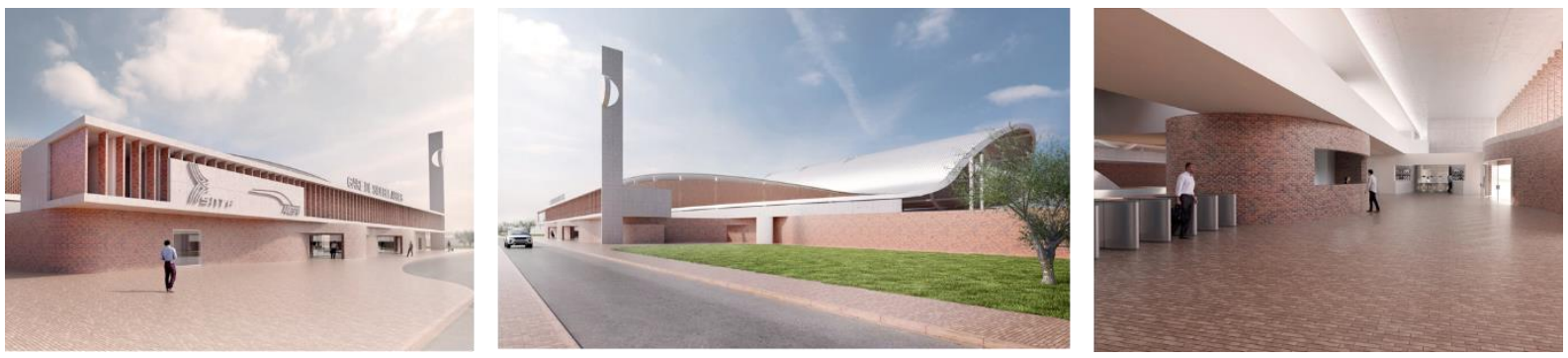

Figura 6: Exemplos de imagens foto-realistas produzidas conforme o processo descrito. 


\subsection{Realidade Virtual}

Os simuladores atuais de Realidade Virtual (RV) representam o culminar de ideias como a de Ivan Sutherland, que em 1965 no seu artigo "The Ultimate Display", o descreve como "(...) uma sala na qual o computador conseguiria controlar a existência da matéria” [3]. Em 1968 concebe o que é considerado o primeiro sistema de Head-mounted display (HMD) de RV, designado de "Sword of Damocles". Atualmente, estes simuladores estão a ser banalizados através das soluções apresentadas pela Oculus Rift, Samsung Gear VR, HTC Vive, Microsoft HoloLens e Google Cardboard, entre outros.

No nosso caso de estudo, explorou-se uma solução tecnicamente semelhante ao princípio da Google Cardboard, que tem como hardware um kit de headsets, para suporte de um smartphone, e um comando Bluetooth. A aplicação utilizada foi a Kubity, da SPK Technology. Para a utilização desta aplicação o fluxo de trabalho foi o seguinte: exportar o modelo BIM para o formato .skp (sketchUp) recorrendo ao plugin rvt 2 skp; executar o upload do ficheiro .skp para a conta de utilizador kubity a partir de um web browser; digitalizar com a aplicação Kubity Go do smartphone o código QR gerado para navegar no modelo em modo RV (Figura 7).

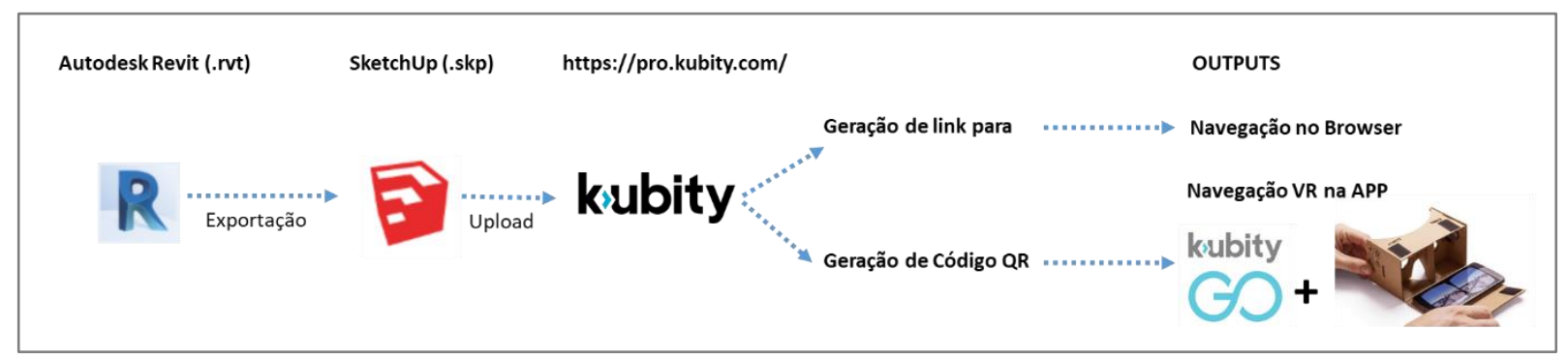

Figura 7: Diagrama do processo de integração de Realidade Virtual.

Para a entrega final ao DO, o modelo utilizado para RV foi o que resultou do processo de texturização em SketchUp para realização das visualizações tridimensionais foto-realistas.

$\mathrm{O}$ facto desta solução permitir a visualização do modelo por qualquer utilizador que tenha acesso ao link, ou ao código QR gerados, quer a partir de um web browser, quer a partir do smartphone, proporcionou ao DO uma experiência mais imersiva com o projeto, tendo sido um aspeto de grande satisfação. Para a equipa de projeto, permitiu que os ajustes realizados ao projeto pudessem ser revisitados, como forma de clarificar questões inerentes à forma, materialidade e sobretudo à escala do edifício.

\section{Coordenação 3D e Colaboração}

O processo coordenação 3D num projeto desenvolvido em BIM serve-se de software de clash detection, que através da comparação dos modelos, deteta conflitos entre as diferentes disciplinas. As plataformas de Common Data Environment (CDE), permitem a colaboração em tempo real, aproximando as equipas geograficamente dispersas.

No nosso caso de estudo o processo de Coordenação 3D esteve intimamente ligado com uma das plataformas de colaboração utilizadas: Autodesk BIM 360 Design. A viabilização destes processos resulta da colaboração estreita entre os perfis de BIM Manager e BIM Project Coordinator, pois enquanto o primeiro se envolve com a criação da infraestrutura de 
colaboração e suporte ao projeto BIM (plataformas), o segundo utiliza essa infraestrutura por forma a coordenar o projeto de modo eficiente. Desta colaboração resultou o BIM Execution Plan (BEP) e a solução de CDE adaptada às circunstâncias da equipa, que apresentamos nos pontos seguintes.

\subsection{BIM Execution Plan}

A última fase do projeto, Avant Projet Detaillé envolveu a colaboração de equipas geograficamente dispersas. Para facilitar o processo colaborativo, todos os fluxos de trabalho envolvidos no âmbito de cada uso BIM foram definidos no BEP com a participação de todos os projetistas. Este documento fundamental sintetiza a informação essencial que deve ser do conhecimento de todos os intervenientes, para que o projeto em BIM se concretize.

Com base em referências existentes sobre o tema [2], levou-se a cabo uma análise dos riscos associados à implementação de cada uso BIM, com as respetivas medidas de mitigação, e cristalizaram-se em diagramas de processos os fluxos de trabalho inerentes, sendo tudo incluído no BEP. Como produto final, que foi sendo atualizado durante o projeto, resultou um documento que desenvolveu os seguintes temas principais:

- Caracterização geral do projeto;

- Contactos dos responsáveis BIM por fase de projeto;

- Objetivos do projeto e usos BIM;

- Processo de execução do projeto BIM;

- Estrutura dos modelos BIM do projeto;

- Caracterização das trocas de informação e nível de detalhe dos modelos;

- Configurações dos modelos;

- Produtos do modelo a entregar;

- Infraestrutura tecnológica;

- Procedimentos de colaboração e agenda do projeto.

\subsection{Plataformas de Common Data Environment (CDE)}

Tecnicamente, o projeto em modo colaborativo e a sua coordenação foram viabilizados por uma solução de $C D E$ com base em 2 plataformas com alojamento em cloud: o Microsoft SharePoint e o Autodesk BIM 360 Design (Figura 8).

A plataforma SharePoint foi utilizada para partilha dos requisitos de projeto e do BEP entre as várias equipas envolvidas e para o alojamento da documentação escrita de cada disciplina, tanto durante o desenvolvimento do trabalho, como da versão final. Sendo uma plataforma com interface em web browser e que permite a edição de documentos Microsoft, foi possível o trabalho simultâneo nos documentos, incluindo o BEP, pelos vários elementos da equipa. A sua utilização implica a criação de um site específico para o projeto, dentro do qual se definiu a estrutura de arquivos que permitiu a cada usuário o desenvolvimento e partilha dos entregáveis. A plataforma BIM 360 Design foi utilizada para o alojamento dos modelos BIM para possibilitar a realização do projeto em modo colaborativo, a sua coordenação $3 \mathrm{D}$ e gestão da sua documentação. Em termos práticos, no processo de troca de informação interdisciplinar, o facto de todos os arquivos de trabalho serem geridos numa única plataforma, elimina a necessidade de download de arquivos e de upload em plataformas distintas. Este fluxo de 
trabalho permite que os projetistas colaborem de modo mais sincronizado, reduzindo erros e a necessidade de retrabalho.

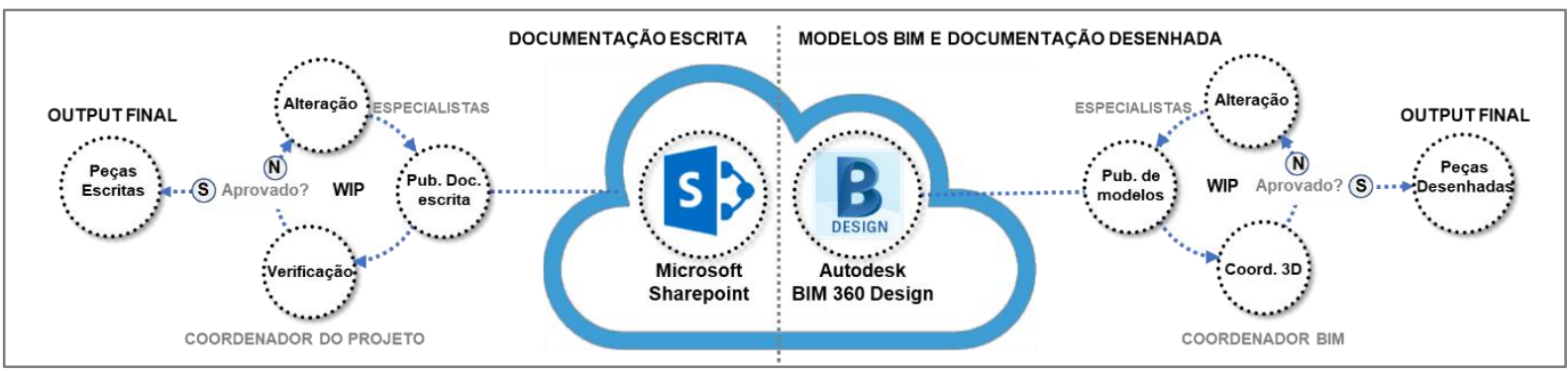

Figura 8: Diagrama do processo inerente ao uso de Coordenação 3D e Colaboração.

Para efeitos de coordenação 3D e visualização, a interface com o utilizador é realizada também a partir de um web browser, sem necessidade de ter o Revit instalado. O BIM Project Coordinator no decorrer da sua análise, identifica as colisões ou dúvidas a esclarecer, emitindo um issue, ou ocorrência, às especialidades envolvidas, acompanhado de uma descrição (Figura 9). Cada ocorrência implica uma reação ou alteração da parte das disciplinas envolvidas. Este ciclo de revisão é repetido até a ocorrência ser encerrada pelo BIM Project Coordinator.
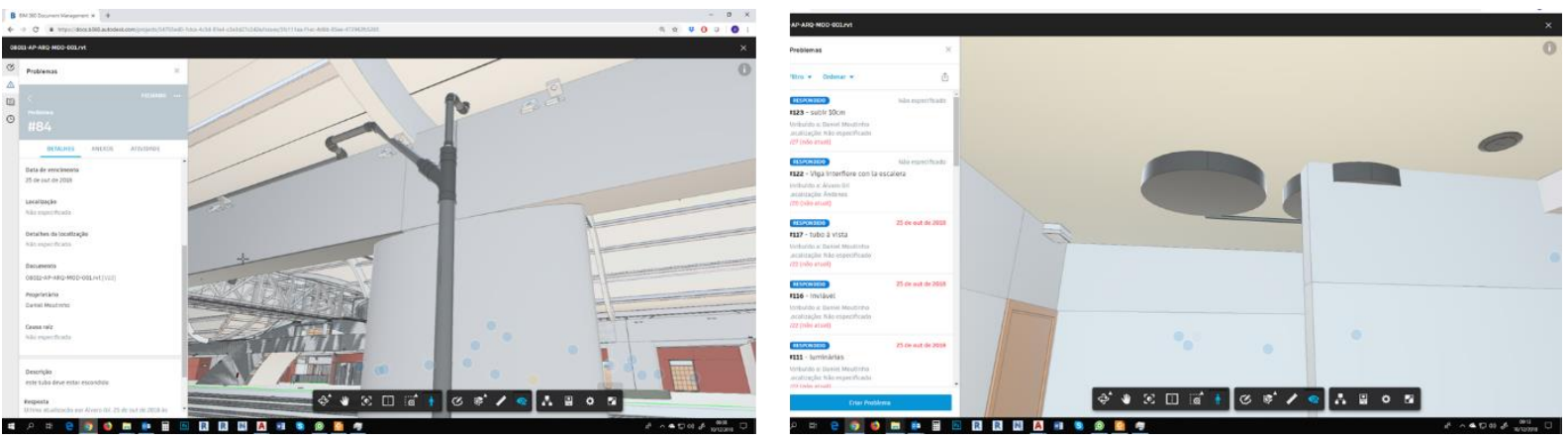

Figura 9: Exemplos de colisões detetadas no BIM 360 Design.

\section{Quantificação Automática e Orçamentação}

A utilização da metodologia BIM para a automatização de processos de quantificação e orçamentação revela-se muito vantajosa, sobretudo nas fases iniciais do projeto, por permitir incluir os fatores "quantidade" e "custo" com base nos elementos modelados, garantindo que este se confina ao budget do DO. No nosso caso de estudo, reuniram-se condições para implementar estes usos na última fase de projeto. Os fluxos de trabalho introduzidos decorrem do processo descrito no ponto "2.2 Pormenorização construtiva e descrição dos elementos" (Figuras 4 e 10).

As listagens de quantidades vão sendo criadas à medida que o código keynote vai sendo atribuído aos diferentes elementos. A nomenclatura de codificação de cada lista de materiais ou componentes construtivos incorpora o código do capítulo do mapa de quantidades para permitir o trabalho de sistematização de informação a realizar pelo Medidor BIM, que é o responsável 
pela verificação da informação a quantificar, extração das quantidades a partir dos modelos, e pela concretização do Mapa de Quantidades e da Estimativa Orçamental a entregar ao DO. Estes documentos são gerados com base no ficheiro .xls (Excel), de gestão de dados para keynotes, ao qual são adicionadas as quantidades de cada artigo, extraídas das tabelas exportadas do modelo Revit, e o seu custo unitário.

Este processo permite que a construção do modelo BIM integre os artigos que se pretendem medir. Durante este procedimento, o Medidor BIM, em coordenação com o Arquiteto, tem a oportunidade de executar o refinamento semântico de cada artigo, para que este seja coerente em todas as peças do projeto.

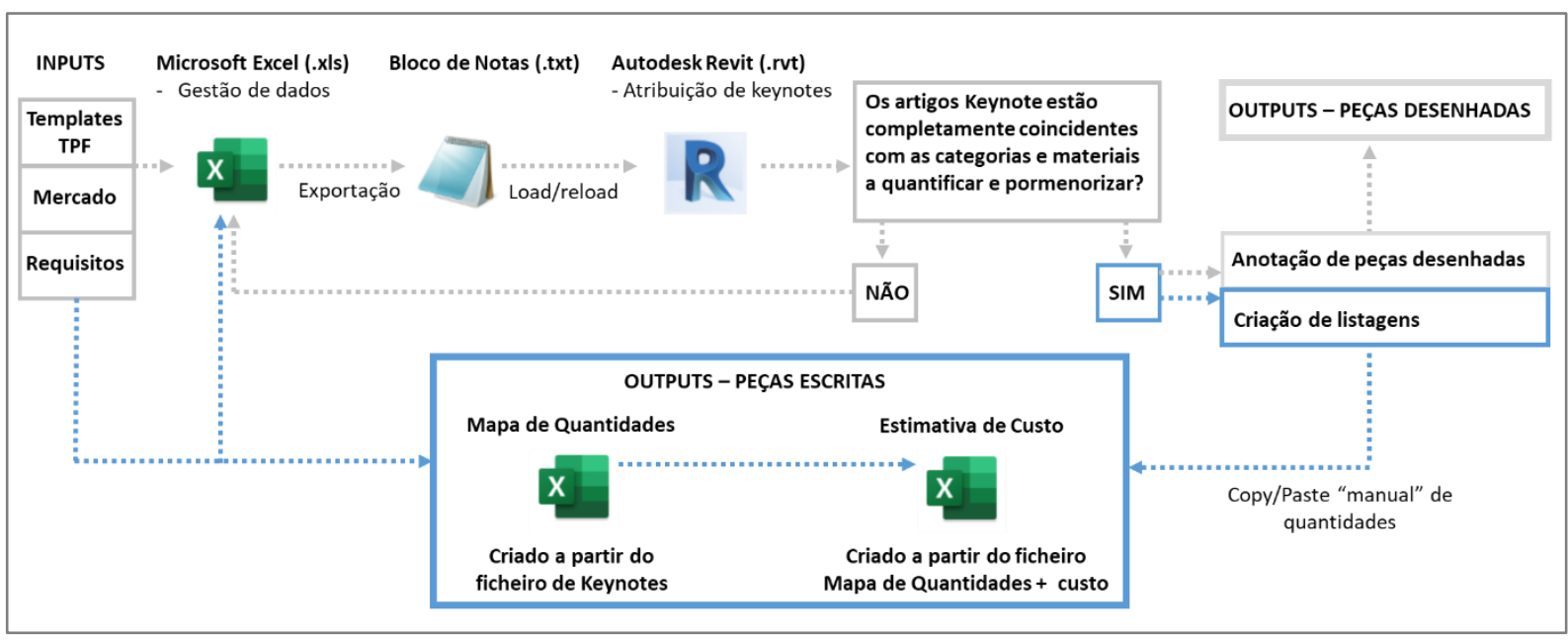

Figura 10: Diagrama inerente ao uso de Quantificação Automática e Orçamentação.

\section{Conclusões}

De um modo geral, a qualidade da documentação produzida em BIM permitiu aproximar o DO, desde muito cedo, de temas complexos que extravasavam a orgânica interna do edifício, contribuindo para a tomada de decisões de modo mais informado.

Destacamos a importância dos processos que envolveram a interoperabilidade entre folhas de cálculo Excel (keynotes) e o software de modelação Revit, para a otimização do método de anotação dos pormenores construtivos, automatização da quantificação e orçamentação. Este processo foi muito valorizado pela equipa de arquitetura por permitir o refinamento da informação do projeto, utilizando as bases de dados que a empresa já possuía. Para além disso, representa uma forma de colaboração inclusiva, pois facilitou o envolvimento de colaboradores sem experiência BIM, mas com grande experiência em projeto e construção.

A solução de RV implementada, embora envolva mais duas plataformas para além do Revit, revelou-se expedita de implementar no fluxo de trabalho do projeto. Contudo, alertamos para os seguintes aspetos: esta solução implica que o smartphone seja compatível com a aplicação Kubity Go; dependendo da complexidade do modelo BIM, nem sempre é possível executar o seu upload na plataforma Kubity; os materiais perdem propriedades no processo de exportação do Revit para SketchUp. Para uma representação mais realista, os modelos têm que ser trabalhados em SketchUp para melhorar a experiência de RV. 
No que se refere ao BEP, embora este documento tenha integrado conteúdos fundamentais que otimizaram o projeto colaborativo, não permitiu uma consulta prática o suficiente para ser integrada de forma natural nos fluxos de trabalho, devido ao seu formato, que resultou demasiado extenso.

A solução de CDE revelou-se estável. Porém, entende-se que a utilização de duas plataformas distintas é uma limitação, por dispersar a documentação do projeto e por dificultar a adaptação das equipas.

Para concluir, existe a perceção clara de que os processos descritos contribuíram para tornar os fluxos de trabalho mais eficientes. Foi possível distribuir o tempo dedicado a cada uma das inúmeras tarefas que envolvem o projeto de modo diferente do habitual, potenciando a sua qualidade. Optamos por investir o tempo poupado em tarefas operativas, de coordenação e documentação, em tarefas conceptuais. Por acreditarmos que a automatização das primeiras será tendencialmente extensível às empresas de projeto, entendemos que será na componente conceptual, que necessita de tempo para ser amadurecida, com pesquisa, experimentação, reflexão, criatividade e intuição, onde poderá residir o fator de distinção concorrencial.

\section{Desenvolvimentos Futuros}

Pretende-se que os usos de Quantificação Automática e Orçamentação sejam incorporados nas fases iniciais do projeto para suportar o processo de decisão. Os processos descritos decorreram do uso de plataformas que não estão especialmente vocacionadas para estes usos BIM. Por esta razão, existem ainda muito aspetos que podem ser melhorados, como o desenvolvimento de rotinas de exportação que evitam a dependência de tarefas manuais de transferência de informação para os outputs finais. Estão-se a explorar processos que envolvem o uso de keynotes como forma de se integrarem sistemas de classificação internacionais e se agilizar o processo de realização de Cadernos de Encargos. A implementação de plataformas específicas que agreguem os modelos BIM de todas as especialidades também está a ser avaliada, para ser introduzida de forma sustentável e permanente. No que se refere ao BEP, está a decorrer um esforço de revisão no sentido de o tornar mais sintético e utilitário para futuros projetos.

\section{Referências}

[1] Kreider, Ralph G. and Messner, John I. (2013). "The Uses of BIM: Classifying and Selecting BIM Uses". Version 0.9, September, The Pennsylvania State University, University Park, PA, USA. http://bim.psu.edu.

[2] Computer Integrated Construction Research Program. (2011). "BIM Project Execution Planning Guide - Version 2.1.” May, The Pennsylvania State University, University Park, PA, USA.

[3] I. E. Sutherland, "The Ultimate Display", Proceedings of the IFIP Congress (1965), pp. 506-508, London: Macmillan and Co., 1965. 